\title{
Марк УРАЛЬСКИЙ
}

\section{«НЕЛЬЗЯ ЛИ КАК МОЖНО СКОРЕЕ КОРРЕКТУРУ?»}

\section{Переписка Ивана Бунина с Вадимом Рудневым 1933-1934 годов}

\begin{abstract}
Аннотация. Статья посвящена истории переписки Ивана Бунина с Вадимом Рудневым (1933-1934 годы), главным редактором эмигрантского парижского литературного журнала «Современные записки».
\end{abstract}

Ключевые слова: И. Бунин, В. Руднев, «Жизнь Арсеньева», «Современные записки», переписка, корректура.

Восемь писем Ивана Бунина и два Вадима Руднева, ведущего редактора «Современных записок» ${ }^{1}$, из собрания Софьи Прегель - Вадима Руднева в архиве библиотеки Иллинойского университета в Урбане-Шампейне ${ }^{2}$ были любезно предоставлены мне их хранителем. Все письма рукописные и носят сугубо деловой характер, то

Марк Леонович УРАЛЬСКИЙ, прозаик, поэт, переводчик с немецкого. Сфера научных интересов - история русского зарубежья и русского литературно-художественного андеграунда XX века. Автор ряда книг и статей по указанной проблематике, а также сборников лирики. Живет в Германии. Email: mark.uralski@gmail.com.

1 «Современные записки» - один из главных литературных журналов эмиграции первой волны, выходивший в Париже с 1920-го по 1940 год (всего вышло 70 номеров).

${ }^{2}$ UIUC: S. Pregel/V. Rudnev. Box 4. 
есть имеют прямое отношение к редакторской деятельности В. Руднева в журнале.

По всей видимости, бумаги Руднева были переданы на хранение в конце 1940-х годов его вдовой В. Рудневой своей доброй знакомой Александре Прегель, дочери старых друзей и однопартийцев М. Цетлиной и Н. Авксентьева, с начала 1940-х годов проживавших, как и она сама, в Нью-Йорке. От нее письма попали к родной сестре ее мужа Софье Прегель, известному литератору, издателю и общественному деятелю русского зарубежья.

Письма Бунина написаны в 1933-1934 годах, и лишь последнее, адресованное жене Руднева, датировано 1941 годом. Письма самого Руднева к Бунину - это черновики, относящиеся к началу 1934 года. Данная переписка является ценным дополнением к реконструкции полной биографии Бунина, поскольку проливает свет на обстоятельства жизни писателя в последние месяцы перед присуждением ему Нобелевской премии по литературе (9 октября 1933 года). Кроме того, она интересна и в сугубо литературоведческом плане - как документальное свидетельство на редкость трепетного отношения Бунина к печатанию своих текстов, в том числе и с точки зрения неукоснительного соблюдения при их редактуре дореволюционных грамматических норм.

В дневниках Бунина за 1933 год [Устами...] имя Руднева не упоминается, да и в целом об их личных контактах известно не так уж много. Этот пробел отчасти восполняют публикуемые письма, которые позволяют судить о характере отношений между одним из самых деятельных редакторов «Современных записок» и их неизменным автором $^{3}$.

3 «Иван Алексеевич Бунин - долголетний и близкий сотрудник журнала <...> его произведения появились в 20 книжках “Современных Записок”, включая и “Митину Любовь”, и “Жизнь Арсеньева”, и целый ряд рассказов: “Дело корнета Елагина”, “Солнечный удар”, “Цикады”, “Воды многие”, “Божье Древо” - большую часть всего, напечатанного Буниным за границей». См. [От редакции]. Здесь и далее предположительное - в угловых скобках, а зачеркнутое - в квадратных. 
Основанные правыми эсерами «Современные записки» были самым известным и авторитетным журналом русской эмиграции первой волны либерально-демократической направленности [Осовский]. Материальную поддержку издателям журнала с самого его основания оказывало правительство молодой Чехословацкой республики [Шруба: 40]. По авторитетному мнению Г. Адамовича, этот журнал - один «из двух-трех лучших журналов, какие были <когда-либо>, в России», ибо они «не только поддерживают прошлое и настоящее, но думают и о будущем» [Вишняк: 11].

В 1928 году один из редакторов «Современных записок» - Фондаминский-Бунаков ${ }^{4}$. Он создал при журнале одноименное издательство и до 1940 года выпустил в нем 54 книги (преимущественно авторов журнала, в их числе и Бунина).

Если Иван Алексеевич Бунин не нуждается в представлении, о его корреспонденте - Вадиме Викторовиче Рудневе - необходимо сказать несколько слов. Этот социалист-революционер, активный участник Февральской революции 1917 года, в эмиграции приобрел большую известность и авторитет как общественный деятель. Он способствовал развитию православных приходов, русских церковных школ, принимал участие в работе благотворительной и культурно-просветительской организации «Православное дело», активно занимался издательской деятельностью. Однако главным и любимым детищем Руднева до конца его жизни были «Современные записки».

${ }^{4}$ Илья Исидорович Фондаминский (литер. псевд. - Бунаков) (1880-1942) - публицист, общественно-политический деятель, редактор, издатель. Видный деятель партии эсеров. В 1917 году комиссар Временного правительства на Черноморском флоте, член Учредительного собрания. В 1919 году эмигрировал. Жил в Париже. Один из основателей и соредактор журнала «Современные записки». Во время Второй мировой войны руководил отправкой евреев в США. От своей визы отказался. В 1942 году отправлен в Аушвиц, где и погиб в лагере. В 2004 году решением Священного Синода Константинопольского Патриархата был причислен к лику святых. 
Когда немцы вошли в Париж, Руднев посчитал за лучшее немедленно покинуть город:

«Ему вместе с женой пришлось пройти пешком больше 500 километров, порою спасаясь от обстрелов немецких аэропланов и ночуя в открытом поле». Рудневы попали сначала в Нерак (Nérac); в начале сентября они перебрались в По и колебались - уехать ли вслед за Авксентьевыми и Вишняками в США, вернуться ли в оккупированную зону и переждать войну на деревенской даче в Feularde 6 . Решение осложнялось состоянием здоровья Руднева < ...> Примечательно, что Руднев, несмотря на положение беженца и совершенно неопределенное будущее, отсутствие каких бы то ни было средств и - смертельную, как вскоре оказалось, - болезнь, все еще надеялся продолжить дело своей жизни и выпустить очередную, 71-ю, книгу журнала <...>

Однако болезнь Руднева была <...> злокачественная опухоль желудка на поздней стадии. Операция рака, проведенная в начале ноября, не смогла его спасти. Мечтания Руднева о продолжении С3 не сбылись. 20 ноября 1940 года его не стало. Жена Руднева, Вера Ивановна, жила во Франции до мая 1941 года, затем уехала в США [Шруба: 128-129].

Как личность «Руднев был честнейшим, милейшим, добрейшим русским интеллигентом, дворянином, земским врачом и эсером» [Яновский: 28], человеком, в котором сочетались «противоречивые черты. Он был порой до застенчивости скромен и совестлив и в то же время мог быть неуступчивым и авторитарным, упорно настаивать на своем и придирчиво следить за тем, чтобы то, что ему казалось нужным и правильным, исполнялось именно так, как он того желал и требовал» [Вишняк: 58-59]. Поэтому, несмотря на репутацию излишне придирчивого редактора, авторы, и в их числе Бунин, как явствует из нижеприводимых писем, считали его душой журнала.

${ }^{5}$ По - город на юго-западе Франции, расположенный у самого подножия Пиренеев.

${ }^{6}$ Le Feularde - деревенское местечко в долине Луары. 
Первое обращение Бунина к Рудневу из публикуемой в настоящей статье их переписки, датируемое 25 апреля 1933 года, по форме является просительным письмом. Это одно из множества ему подобных писем, которые Бунин рассылал своим издателям и благодетелям в течение всей своей эмигрантской жизни за исключением «пятилетки благоденствия» (1934-1939 годы), последовавшей за получением им долгожданной Нобелевской премии по литературе, освободившей его на время от мучительных финансовых забот:

Дорогой Вадим Викторович,

пожалуйста, простите за преждевременность, но я истинно в отчаянном положении, в большой нужде: если можно, сделайте милость, вышлите хоть что-нибудь в счет моего гонорара.

Сердечно Ваш Ив. Бунин

Следует помнить, что из 33 лет своей эмигрантской жизни добрых четверть века Бунин прожил в тяжелой нужде. 1933 год не был в этом отношении исключением. Из-за постоянного гнета материальных забот душевное и физическое здоровье еще совсем не старого писателя (Бунин был на 53 году жизни) оставляло желать лучшего. Об этом в частности свидетельствуют дневниковые записи Буниных [Устами... 279-299] за 1933 год. Например, 27 мая 1933 года Вера Муромцева-Бунина пишет в дневнике:

Проснулась рано. Ян встал раздраженный <...> он в ужасе от своего писания - был в каком-то припадке тихого отчаяния. Он переутомился. Безденежье. Однообразие. Неврастения [Устами ... 282].

Четырьмя месяцами позже, 5 сентября 1933 года, она отмечает:

Нам придется две недели быть без мяса, ибо Ян выдает по 25 фр <анков > в день [Устами... 289].

Приводимые ниже письма Бунина к Рудневу относятся к концу лета 1933 года. В части, касающейся присылки корректуры текстов, речь идет о публикации глав XV- 
XXI пятой книги «Жизни Арсеньева» в № 53, вышедшем в свет 12 октября 1933 года. В коротком письме без даты (возможно, от начала июня 1933 года) Бунин приглашает Руднева посетить его на дому «(1 ru Jacques Offenbach, 5 этаж)», предварительно созвонившись:

Условимся только, когда мне вас ждать. Позвоните по телефону - лучше всего от 1 часа до 2-х часов или в 7 (до 8) вечера.

Однако встреча эта, по-видимому, не состоялась, так как 14 июня 1933 года Бунин пишет Рудневу:

Дорогой Вадим Викторович,

очень, очень жалею и я, что не удалось повидаться, простите, что не проявил к тому усилий, - знал, как Вы всегда заняты, и надеялся к тому же, что хоть на минутку увижу Вас на Тургеневском собрании ${ }^{7}$. Очень тронут опять Вашим добрым расположением ко мне, сердечно благодарю за выписку из письма Бицилли, всячески постараюсь дать продолжение «Арсеньева» именно в ближайшую книгу, но, повторяю, при том условии, что Бог даст здоровья, - я все еще теряю кровь чуть ли не каждый день ${ }^{8}$, и если журнал не будет торопить меня, даст мне самый крайний срок: я ведь всегда расстаюсь с рукописью с большой тревогой, с большими сомнениями <..> От души обнимаю и целую Вас, кланяюсь В<ере $>$ И<вановне $>$.

Ваш Ив. Бунин

Бунин, по всей видимости, не прислал свой текст вовремя для публикации в «ближайшей книге» журнала № 53, поскольку, как явствует из письма от 14 августа 1933 года, находился в весьма болезненном состоянии. Это письмо Бунина носит извинительный характер и содержит детальное описание ощущений, которые писатель испытывает при мучивших его геморроидальных крово-

${ }^{7}$ Имеется в виду мероприятие по поводу 50-летней годовщины со дня смерти И. Тургенева.

${ }^{8}$ Бунин страдал сильными геморроидальными кровотечениями. 
течениях. Изложение Буниным столь интимных подробностей своей болезни в деловом письме свидетельствует о высокой степени доверительности его отношений с адресатом. Кроме того, Руднев был дипломированным врачом (он окончил медицинский факультет Базельского университета), хотя в эмиграции и не практиковал.

Дорогой Вадим Викторович,

очень рад, что Вы не сердитесь на меня, что я невольно обманул вас - это вышло истинно невольно: я не ожидал, что <...> буду хворать (то есть терять кровь) < ..> и испытывать все, что полагается в таком случае: тревогу, тупость, нерешительность; или что хуже всего, пароксизмы неожиданной и чаще всего безрассудной решительности перед кровью (то есть перед началом кровотечения. - M. У.) и слабость, безмятежность после нее. Так что для работы остаются только некоторые светлые промежутки, коих, конечно, было бы чересчур мало, не будь у меня, дай Бог не сглазить, способности < ..> быстро оправляться от всяких своих неприятностей. От всей души благодарю Вас за новые добрые слова о моей работе и за готовность еще некоторое время ждать меня. Но лучше не ждите, очень боюсь подвести Вас, и тем более боюсь, что за последние дни дела мои еще ухудшились, за эти последние дни (верно, оттого, что я стал ходить купаться) кровь пошла так бурно, что это уже напоминает несчастный месяц прошлого года. Когда я недели три лежал совсем пластом с утра до вечера, подкладывая под себя лед и глотая chlorure de calcium ${ }^{9}$. M<0жет $>\sigma<$ ыть $>$, кровь и остановится, - принял самые решительные меры, так что вчера и ночью - тьфу, тьфу, сухо дерево! - ее нет, ну а если не остановится? Голова моя во всяком случае достаточно глупа даже и сейчас. Прибавьте к этому еще и весьма серьезную жару, наступившую у нас дней десять тому назад.

Сердечно обнимаю Вас и прошу не серчать: мне и самому хотелось бы написать побольше, да вот видите, какие обстоятельства (<можно бы> сказать - вот сделал бы опять операцию, - после первой, в 26-ом году, я истинно воскрес на не-

${ }^{9}$ Хлористый кальций. 
сколько лет, - но теперь по моей нищете об этом и думать нечего!).

Поклон милой Вере Ивановне.

Ваш Ив. Бунин

В недатированном сопроводительном письме - по всей видимости, от начала 20-х чисел августа 1933 года - Бунин сообщает об отсылке своего текста в редакцию журнала:

Дорогой Вадим Викторович,

простите, что так поздно посылаю (рукопись текста. M. У.) - совсем никуда, так плохо себя чувствую. Да к тому же Вы, верно, только что вернулись из деревни. И<лья $>$ И $<$ сидорович $><$ Фондаминский $>$ уехал, а где $\mathrm{M}<$ ихаил $>$ $\mathrm{O}<$ сипович $><$ Цетлин $>-$ не знаю.

Нельзя ли как можно скорее корректуру? Очень нужно послать переводчику шведскому поскорее. (Позвольте напомнить - корректуру дайте в двух экземплярах.)

28 августа 1933 года Бунин пишет Рудневу новое письмо.

Дорогой Вадим Викторович,

получил < ...> от Вас < ..> прочел и шлю назад <корректуру $>$.

Пожалуйста, простите, что еще раз беспокою - покорнейшей просьбой, прислать <еe> еще раз, в сверстанном виде, какой надеюсь оставить уже неприкосновенным.

«С жинкою» - нельзя, не выходит даже по ритму песни ${ }^{10}$. На счет «міни» не знаю, что сказать. Конечно это ошибка в моей рукописи - «мени», надо «міни» ${ }^{11}$, но десятичное ли «і»? Пишу < ..> грубо, на русский лад, ставя везде «и» восьмеричное, ибо даже сами формы всегда спорят, где надо восьмеричное, где десятеричное ${ }^{12}$.

${ }^{10}$ Речь идет о предложении: «Они говорили, а я слушаль: “Ой, на ropi та женщі жнуть...”.

${ }^{11}$ В той же песне: «Мені з жинкою / Н’ возиться!»

${ }^{12} \mathrm{I}, \mathrm{i}$ - буква из кириллических алфавитов, существовавшая в русской письменности до реформ 1917-1918 годов. Числовое значение буквы I в кириллице, как и в греческом алфавите, - 10, отсюда распространенное название «И десятеричное», использовавшееся для отличия от буквы И (иже), называвшейся «И восьмеричное». 
«Галлерея» и «Терраса» пусть будет по Вашему (речь идет о правописании этих слов. $-M .{ }_{\text {.). }}$.

Очень снова утешен Вашей похвалой. Совершенно искренне говорю: самому кажется все не так, как бы нужно было... Это моя давнишняя болезнь, очень меня мучающая. Когда дело доходит до печатания. Здоровье теперь ничего себе - купаться бросил.

Любящий Вас Ив. Бунин

На этом переписка, связанная с публикацией пятой книги «Жизни Арсеньева» в № 53 журнала, заканчивается. А буквально через месяц после выхода в свет октябрьской книги журнала в жизни Бунина произошел коренной переворот: 9 ноября 1933 года ему была присуждена долгожданная Нобелевская премия по литературе. В силу этого обстоятельства Бунин, вертевшийся в круговороте нобелевских торжеств, порядком ими измученный и опустошенный, был явно не в состоянии работать над своими текстами. В этой связи он в посланной им Рудневу почтовой открытке «экспресс» отказался от публикации новых глав «Жизни Арсеньева» в № 54. На этот «экспресс» писателя Руднев отозвался подробным письмом от 5 ноября 1933 года.

\section{Дорогой Иван Алексеевич!}

Получил Ваш экспресс и очень Вас благодарю за скорый и ясный ответ: с Вами деловую переписку приятно вести даже когда приходится получать неприятные вести, как сейчас - отказ нам в «Арсеньеве», так Вы всегда быстры, отчетливы и сердечны в своих ответах.

Не хочу, не считаю себя вправе больше Вас мучить, дорогой Иван Алексеевич, оказывать моральное давление на Вас. Пусть будет так, считайте себя совершенно свободным от всяких обязательств. А для Вашего душевного спокойствия обещаю даже планировать книжку 5 «С» и во втором варианте без Бунина.

Но только в надежде на лучшие дни, на добрые результаты Вашего самолечения и ссылаясь на Ваши собственные «опасные мысли» в этом письме, - позвольте <..> всей душой по-прежнему желать восстановления варианта с Буни- 
ным, а для этого - оставить соответствующие возможности. Одну из них - для продления срока, Вы сами любезно подсказали: если бы поместить «Арсеньева» в конце литературного раздела, то рукопись можно было бы представить с отсрочкой, к декабрю (выйдет книжка <..> не в конце, а в начале января!). Другую - сохранить возможность без обиды для кого-либо <..> снять вещь <..> я ясно вижу, как все по-хорошему это сделать.

Итак, никаких тяготящих над Вами обязательств, но, если б удалось докончить работу <..> даже за месяц, - будем ужасно, от души рады выпустить книжку последнюю этого года, или начальную 1934 - с продолжением «Арсеньева».

Далее в черновике Руднева отчеркнута часть письма, которую он, после некоторых размышлений, решил не приводить в чистовике:

Сейчас нам предстоит тяжелая работа: вновь собираемся начать по примеру прошлого года компанию по полупринудительной подписке 100 франковой... Положительно не мирится душа с тем, чтобы «СЗ», единственный (не смотря на «Числа» $\left.{ }^{13}\right)$ русский журнал, оказался закрытым из-за недостатка буквально нескольких тысяч на книжку! Тяжело приставать к богатым и равнодушным людям, но таков закон нашего века, ничего не поделаешь! Сейчас очень мило и горячо (надолго ли?) взялся нам помогать В. М. Маклаков. Веду сложную дипломатию «за пределами фракции». Обложены (на Земгор еще пойманы) два-три крупных зверя [буржуя] < ..> Конечно, большинство наших <заходов > сорвется, кое-где со срамом даже, но неужели же не будет и удач?? У меня в душе чувство, что «СЗ» вытащить на этот год все же удастся. И ужасный берет азарт непременно все для этого сделать. Без возни с милым нашим журналом жизнь станет вовсе уж опустошенной. Ну, дай Бог нам всем еще увидеть лучшие дни. Обнимаю Вас, Ваш

В. Руднев

13 «Числа» - литературный журнал эмиграции первой волны. Выходил в Париже в 1930-1934 годах. 
Читая это письмо, нельзя не вспомнить слова М. Вишняка о том, что на Рудневе

лежала <..> задача - добывание необходимых журналу средств <...> дотации «Современным Запискам» все уменьшались, в то время как расходы по изданию журнала - типография, бумага, оплата авторов при возраставшей дороговизне все увеличивались. В течение годов Руднев вел огромную и утомительную переписку со всеми, кто прямо или косвенно мог содействовать продлению жизни «Современных Записок», журнал не раз дышал на ладан из-за отсутствия средств <... В. Рудневу приходилось <..> в личных беседах доказывать, уговаривать, просить, обещать, драматизировать, «браниться», - всеми силами «вымогать», как он выражался, необходимые суммы. Надо было знать Руднева, чтобы по справедливости оценить его усилия. Это было совершенно не в его натуре, стиле и духе. Но он не отступал и, не считаясь с временем, трепкой нервов и душевным насилием над собой, снова и снова писал, приставал и, в конечном счете, - с затяжками, сокращениями, предупреждениями, что это уже окончательно в самый последний раз, - все же добивался очередного продления существования «Современных Записок». Руднев ни в какой мере не был дипломатом, не любил и не умел лавировать и маневрировать, дорожил достоинством, своим личным и общественным, журнала, и все же вряд ли кому удалось бы успешнее справиться с лежавшей на нем мучительной и благодарной задачей. Он героически боролся за сохранение «Современных Записок» [Вишняк: 58-59].

В этой связи то, что в чистовике письма от 5 ноября 1933 года пассаж о тяжелом финансовом положении журнала отсутствует [Шруба: 95], можно объяснить щепетильностью Руднева. По всей видимости, он, не пожелав делиться с Буниным подробностями борьбы за выживание журнала, полагал, что тот, став теперь богатым человеком, может воспринять его откровения как просьбу подключиться к финансированию издания журнала.

Неизвестно, «получил ли нуждающийся журнал, опубликовавший на своих страницах едва ли не все важнейшие произведения Бунина 1920 годов, от него какую-нибудь 
денежную поддержку, скорее всего, нет. Зато фактом является то, что с 53-й книги, вышедшей в октябре 1933 года, вплоть до 63-й книги, увидевшей свет в апреле 1937-го, Бунин не опубликовал в С3 ни слова ${ }^{14}$. По крайней мере, для издательства “Современные записки”, выпустившего в 1929-1931 годах четыре книги Бунина, присуждение премии обернулось некоторой финансовой пользой - как всегда, Нобелевская премия породила повышенный спрос читателей на произведения лауреата, и Фондаминский, профинансировавший в полном объеме две из этих книг, получил часть своих денег назад» [Шруба: 95-96].

Пятьдесят четвертый номер «Современных записок» вышел в январе 1934 года с фотографическим портретом Ивана Бунина на заставке и двумя статьями-панегириками по случаю присуждения Нобелевской премии русскому писателю-эмигранту - «Оть Редакціи. - И. А. Бунинъ» и «Ф. Степунъ. - ИВ. Бунинъ», но без бунинских текстов. Ну а примерно через месяц после этого знаменательного события, 14 февраля 1934 года, Руднев пишет новое письмо, в котором, как видно из его черновика, изобилующего множеством помарок и зачеркиваний, всячески старается уговорить новоиспеченного нобелевского лауреата не почивать на лаврах, а печатать в журнале продолжение «Жизни Арсеньева».

\section{Дорогой Иван Алексеевич!}

Получил Вашу открытку и сегодня же высылаю Вам 5 экз<емпляров > Вашей книги «Тень птицы» ${ }^{15}$. Достаточно ли?

Пересылаю Вам и письмо для Вас из Варшавы от Н. Буниной (?).

И пользуюсь случаем, чтобы спросить Вас: [дадите ли] рассчитывать ли нам на продолжение «Арсеньева» в ближайшей

14 Здесь имеет место ошибка или опечатка, так как в № 53 публикуется продолжение «Жизни Арсеньева».

${ }^{15}$ Имеется в виду сборник рассказов И. Бунина «Тень птицы», вышедший отдельной книгой в издательстве «Современные записки» (Париж, 1931). 
книжке «С $<$ овременных $>3<$ аписок $>$ ? Я хлопочу не о журнале только, - но не кажется ли Вам, что в Ваших личных интересах теперь выступить [вновь в литерат<уре>] уже не в качестве уважаемой знаменитости $<$ [лауреата] в свое. - неразб. $>$, а в старой [роли] своей писательской роли? Дабы не приходили недругам мысли о лауреате [и лаврах], почившем на лаврах. Шутки в сторону. Дорогой Иван Алексеевич, теперь Вы уже успели осмотреться в своем Грассе? Публика вас не терзает, Вы, конечно, перечли написанную часть Арсеньева - [можно ли] можете ли Вы дать ее нам [в течение марта месяца (до двадцатых чисел марта)] в течение ближайшего месяца?

Итак, Бунин перестал публиковаться в журнале, начиная с 54-й книги, увидевшей свет в январе 1934 года. Только через три года - в апрельском номере 63 (1937 год) были напечатаны фрагменты «Из книги “Освобождение Толстого”». Полностью одноименная книга была выпущена в этом же году парижским издательством «YMCАPress».

Судя по приводимой переписке, никакого разрыва с С3 у Бунина не было, как не было и злокозненности в отказе от присылки журналу своих новых текстов. На основании высказываний Бунина в письмах о том, как до болезненного щепетильно он относится к работе с корректурой своих текстов, можно понять, почему в 1934-1936 годах он вообще не публиковал новых произведений. В эти годы берлинское издательство «Петрополис» выпустило собрание сочинений Бунина в 11 томах. Оно является последним фундаментальным изданием произведений писателя, все тексты в котором даются в авторской редакции. Вполне естественно, что редакторская работа такого масштаба не могла не оказать негативного влияния на творческую активность немолодого уже писателя. Бунину в эти годы, попросту говоря, нечего было давать для журнала.

B UIUC хранится только одно письмо Бунина к Рудневу за 1934 год, не имеющее отношения к теме публикаций произведений Бунина, однако косвенно свидетельствующее о том, что добрых отношений с журналом Бунин не порывал. 
Дорогой Вадим Викторович,

сделайте отдолжение - вышлите, пожалуйста (и поскорее, если можно), последнюю книгу «Соврем<енных> записок» Галине Николаевне, которая сейчас в Германии:

Frau Galina Kouznetzoff

Rosdorfer Weg 14II: bei Rosezberg

Göttingen, Allemagne

Все расходы заплачу Вам лично - надеюсь скоро быть в Париже <..> благодарю и обнимаю Вас, целую дорогую В $<$ еру $>$ И<вановну $>$.

14 ноября 1934, Ваш Ив. Бунин

Последним документом из собрания Софьи Прегель - Вадима Руднева в UIUC является почтовая открытка с соболезнованием по случаю кончины Руднева, посланная Буниным его жене 10 января 1941 года:

Моя дорогая, милая Вера Ивановна, из Вашего письма к В <ере $>$ Н < иколаевне $>$ увидал, что Вы, верно, не получили моей открытки, которую я Вам послал вскоре после вести о Вашем и нашем общем <...> горе. Еще раз выражаю Вам мои самые горячие чувства. Вы знаете, как я любил покойного и как я люблю Вас.

Да храни Вас Бог, обнимаю Вас от всей души.

Ваш Ив. Бунин

\section{Литература}

Вишняк М. В. «Современные записки» (воспоминания редактора) // Indiana University Publications Graduate School (USA). Slavic and East European Series. 1957. Vol. 7.

Осовский О. Сохраняя «духовное лицо» русской литературы: подлинная история «Современных записок» в архивных материалах и примечаниях к ним // Вопросы литературы. 2016. № 1. C. $353-371$. 
От редакции // Современные записки. 1934. № 54. С. 195.

Устами Буниных. Дневники Ивана Алексеевича и Веры Николаевны и другие архивные материалы. В 3 тт. / Под ред. М. Грин. T. 2. Мюнхен. Possev-Verlag, 1981.

Шруба М. История издательства «Современные записки» в свете редакционной переписки // «Современные записки» (Париж, 1920-1940). Из архива редакции. В 4 тт. Т. 1 / Под ред. О. Коростелева и М. Шрубы. М.: НЛО, 2011.

\section{References}

Editorial // Sovremennie zapiski. 1934. Issue 54. P. 195.

From Bunins. Diaries by Ivan Alekseevich and Vera Nikolaevna and Other Archive Materials. In 3 vols. / Ed. M. Grin. Vol. 2. Munich. Possev-Verlag, 1981.

Osozsky O. Preserving the 'Spiritual Image' of Russian Literature: True Story of Sovremennie zapiski in the Archive Materials and Notes to Them // Voprosy literatury. 2016. Issue 1. P. 353-371.

Shruba M. History of Sovremennie zapiski Editorial Staff in the Light of Editorial Correspondence // Sovremennie zapiski (Paris, 1920-1940). From the editorial staff's files. In 4 vols. Vol. 1 / Ed. O. Korostelev and M. Shruba. Moscow: NLO, 2011.

Vishnyak M. V. Sovremennie zapiski (Editor's Reminiscences) // Indiana University Publications Graduate School (USA). Slavic and East European Series. 1957. Vol. 7. 